\title{
La Guerra Civil y el exilio transatlántico en Solo queda saltar: novela de formación femenina de María Rosa Lojo
}

\author{
Camila Bari ${ }^{1}$
}

Resumen. Solo queda saltar plantea la posibilidad de crecer, después de la violencia de la Guerra Civil y del exilio, hacia la libertad. La novela consta de dos partes: el diario autobiográfico de Celia, la hermana mayor, y los recuerdos de la hermana menor, Isolina. Dentro del género Bildungsroman, Celia representa la realización interior y la lucha contra los obstáculos del medio, mientras Isolina encarna la mutua transformación creativa de la heroína y la realidad histórica, forma ideal de la novela de formación según Bajtin. El motivo central de la novela es la guerra y sus secuelas. Celia sufre un intento de violación en la España de la posguerra franquista. Escribir le permite superar sus pesadillas postraumáticas y crearse una identidad narrativa (Ricoeur). La desaparición de su hijo en la represión militar de la insurgencia de los años 70 en la Argentina hará tambalear nuevamente su identidad y cerrará su futuro. La memoria vedada y su recuperación por la palabra en Solo queda saltar puede considerarse como una metonimia de la represión o deformación en la memoria oficial de los sufrimientos padecidos por todo un pueblo a causa de la guerra y su liberación gracias a la literatura. La escritura de Isolina, sin disimular su visión crítica y realista del pasado, se abre hacia el futuro con una identidad dinámica y transcultural que se mueve dentro la frontera transatlántica y le permite concebir un proyecto artístico: la creación de las Siniguales, o seres únicos, inclasificables e inmunes a los estereotipos.

Palabras clave: novela de formación; María Rosa Lojo; Solo queda saltar; Guerra Civil española; exilio republicano.

\section{[en] The Civil War and the Transatlantic Exile in Solo queda saltar: Women's Bildungsroman by María Rosa Lojo}

\begin{abstract}
Solo queda saltar raises the possibility of growing after the violence of the Spanish Civil War and of exile towards freedom. The novel consists of two parts: the autobiographical diary of Celia, and the memories of Isolina, her younger sister. Within the Bildungsroman genre, Celia represents the inner realization and the fight against the obstacles of her historical environment, while Isolina embodies the mutual creative transformation of heroin and historical reality, an ideal form of the Bildungsroman according to Bakhtin. The central motive of the novel is war and its aftermath. Celia suffers an attempted rape in the postwar Franco era in Spain. Writing allows her to overcome her post-traumatic nightmares and create a narrative identity (Ricoeur). The execution of her son in the military repression of the insurgency of the 70s in Argentina will shake her identity again and close her future. The forbidden memory and its recovery by the word in Solo queda saltar can be considered as a metonymy of repression or deformation in the official memory of the sufferings of the people because of war and their liberation thanks to literature. Isolina's writing, without disguising her critical and realistic vision of the past, opens towards the future with a dynamic and crosscultural identity that moves within the transatlantic border and allows her to conceive an artistic project: the creation of Siniguales, or unique beings, unclassifiable and immune to stereotypes.
\end{abstract}

Keywords: bildungsroman; María Rosa Lojo; Solo queda saltar; Spanish civil war; republican exile.

Sumario. 1. Introducción. 2. Solo queda saltar como novela de formación. 3. El motivo central de la guerra y sus secuelas. 4. Memoria, olvido y literatura. 5. Cuaderno de Celia 1948: el reconocimiento narrativo de su identidad. 6. Cuaderno de Isolina 2018: su identidad interactiva, transcultural y abierta al futuro. 7. Una reflexión final.

Cómo citar: Bari, C. (2021) La Guerra Civil y el exilio transatlántico en Solo queda saltar: novela de formación femenina de María Rosa Lojo, en Anales de Literatua Hispanoamericana 50, 49-61.

\footnotetext{
${ }^{1}$ Westminster College, Salt Lake City. EE.UU.

E-mail: camila.baridec@gmail.com
} 
Escríbelo. Regístralo. Apúntalo.

Nadie sabe que dentro de un bloque de mármol hay escondido un cuerpo, una cara, unos ojos que miran los tuyos, hasta que los descubre un escultor.

Así es con lo que sientes, con lo que piensas, cuando lo ves escrito.

(Lojo, 2018: 11)

Como un salto de animales por la rueda de fuego, como una caminata mortal sobre una cuerda de viento, en equilibrio sobre una tierra cortada, en puntas de pie sobre un cuchillo de hielo que se va deshaciendo a cada paso. Así el poema. (Lojo, 2011: 81)

\section{Introducción}

Solo queda saltar plantea la posibilidad de crecer en libertad después de la violencia de la Guerra Civil y del exilio. El exilio se compara con el riesgo de saltar desde lo alto de un acantilado tal como el poeta se lanza a la acrobacia mortal de abandonar lo conocido para inventar un nuevo territorio, una nueva palabra, que sostenga el ser. La narración, con su ritmo ágil e imágenes muy nítidas, despierta la respuesta emocionada de todo tipo de lectores, desde adolescentes hasta adultos, turbados, por un lado, por sus escenas de violencia y, por otro, conmovidos por la calidez de sus personajes. Hay momentos en que la acción es trepidante como en una novela de suspenso, con misteriosas desapariciones y anagnórisis, otros en los que se convierte en una novela policial que llega a ser de terror por la violencia criminal de algunos de sus actores. Tiene, como en toda la narrativa de Lojo, algunas imágenes poéticas muy logradas que contribuyen a la definición de un mundo tan variado como el que presenta al lector.

Solo queda saltar se divide en dos partes; es como un díptico que se abre hacia el mundo interior de Celia en la primera parte y hacia la vida de Isolina, orientada a la acción y a experiencias nuevas, en la segunda. La historia es contada por ellas mismas, dos narradoras que focalizan su relato autobiográfico en su propio yo y en relación con su contexto. El tono de la primera narración es más emocional e íntimo y da relieve al carácter de Celia, con su riqueza de imágenes -incluso visionarias-, símiles y metáforas sorprendentes. El relato de Isolina narra con realismo las memorias de toda su vida, destacando la osadía de sus decisiones aventureras y audaces, poniendo el acento en la interacción con otras personas y con su medio, antes que en los conflictos de su subjetividad.

La cosmovisión de las narradoras y de los personajes en general, en su mayoría inmigrantes, es muy amplia, pues abarca los lazos transatlánticos con países de dos continentes y, a la vez, profundiza en la microhistoria de un país emergente y de una ciudad provinciana, donde la intimidad de sus vidas, sueños o proyectos personales son albergados en la calidez de un hogar argentino de exiliados e inmigrantes gallegos rodeados de asistentes domésticos criollos e indígenas. El cuaderno de Celia describe las diarias costumbres y los ambientes de su familia de sangre por parte de su tío, ampliada por una generosa solidaridad hacia los necesitados de trabajo y auxilio. Narra los eventos que van transcurriendo en su nueva patria, donde todo es nuevo para ella y donde encuentra un lugar de pertenencia y una ocupación de responsabilidad, que acepta inmediatamente. Tanto ella como Isolina entablan en su narrativa constantes comparaciones entre la cultura gallega y la argentina. La ocasión de abrir el baúl que las dos hermanas han traído de España le brinda a Celia la oportunidad de describir con detalle los libros, los manteles de lino bordado, los encajes de la casa familiar en Galicia, que despiertan la emoción del tío emigrado hace tantos años ante el recuerdo de quienes hicieron o guardaron con amor esos objetos. A la par, la narradora va describiendo las comidas típicas y costumbres argentinas.

La lectura de Solo queda saltar puede hacerse desde los parámetros de la novela histórica y, específicamente, de las novelas de la Guerra Civil española, de las guerras contra el indio, y de los enfrentamientos entre insurgentes y militares en Argentina y, como correlato en todas ellas, permite el abordaje desde la problemática de la memoria y del olvido como parte del tratamiento del tiempo en la narración histórica o literaria. También cabe leer la novela desde el punto de vista de la promoción y defensa de los derechos de la mujer conculcados especialmente en épocas de guerra. Por último, la lectura inspirada por el tema de la formación de un ser humano en un ambiente convulsionado es la que categoriza a Solo queda saltar como novela de formación, de educación o desarrollo, la llamada Bildungsroman en la tradición alemana. En realidad, no puede excluirse ninguno de estos enfoques en el análisis de Solo queda saltar pero, 
por la edad de las protagonistas, por sus diferentes formas de relacionarse con el medio y por la personalidad que cada una va desarrollando en la narrativa, es legítimo profundizar en los aspectos teóricos de su estudio como novela de formación.

\section{Solo queda saltar como novela de formación}

Indudablemente, Solo queda saltar es, como tantas novelas de Lojo, una novela histórica en la que, también como en muchas otras, experimenta varias formas narrativas, en este caso el diario y la memoria, ambos relatos autobiográficos de las narradoras protagonistas. Los encuentros y diálogos de éstas con otros personajes permiten volver, en una analepsis salvadora, a recordar el pasado personal que, en el caso de una de ellas, había sido borrado por un trauma psíquico. Sin embargo, Solo queda saltar puede leerse como novela de formación a partir del dilema que en ella se presenta sobre las posibilidades de formarse como persona adulta, a pesar de los recuerdos dolorosos y la pérdida de los padres por causa de una guerra devastadora. ¿Qué clase de madurez se puede alcanzar en medio del violento caos de la guerra? El salto hacia el exilio en un país extranjero y en paz abre una nueva posibilidad a las protagonistas. La niña y la adolescente que llegan a la Argentina desde España logran completar un proceso de formación y de recuperación emocional del que dan testimonio sus anotaciones autobiográficas, que constituyen el cuerpo de la novela.

Mucha teoría y crítica se ha escrito sobre el género novela de formación, llamado también de educación, de aprendizaje o de desarrollo. En 1819, Karl Morgenstern acuñó el término Bildungsroman en una conferencia sobre su naturaleza y lo describe como un género que no solo: "mira hacia el interior, hacia el desarrollo de su protagonista ficticio, sino hacia el exterior, hacia el mundo real tendiendo al desarrollo de su audiencia" (Morgenstern, 2009: 648). Esta tensión entre lo personal y lo histórico va a continuar dominando la investigación posterior sobre el género.

Mijail Bajtin, en su estudio sobre "La novela de educación (o de aprendizaje) y su importancia en la historia del realismo", concentra su investigación en "la imagen del hombre en el proceso de desarrollo en la novela" y deslinda a la "novela de educación" o "de aprendizaje" (Bildungsroman) como subespecie del género novelístico, muy relacionada, sin embargo, con otras formas como la novela autobiográfica, la de pruebas, o la de vagabundeo. Los principios de representación del héroe y su temporalidad difieren en cada una de estas formas novelísticas. En la novela de formación, señala Bajtín la heterogeneidad de los fenómenos que presenta, sin que predomine ninguno de ellos en particular. La novela de formación tiene un carácter esencialmente biográfico o autobiográfico, se puede organizar o no sobre la base de la idea puramente pedagógica acerca de la formación de un hombre o mujer y puede estructurarse según el orden cronológico del desarrollo y educación del o la protagonista, casi sin argumento, o, por el contrario, puede crear una trama compleja y llena de aventuras. Poner o no el acento en uno solo de estos aspectos ha llevado a los teóricos de la novela de formación a limitar o ampliar el corpus que las comprende. Bajtin, en cambio, traza un corpus muy inclusivo desde la antigüedad hasta la novela moderna, dentro del cual destaca las aún más considerables diferencias que tienen que ver con la relación del héroe con el tiempo histórico real. Según Bajtin, los principios constitutivos de la imagen del héroe y de su tiempo histórico preparan la aparición de la novela realista del siglo XIX y, en especial, "la novela de educación que surge en Alemania en la segunda mitad el XVIII tiene una importancia muy especial para el desarrollo de la novela del realismo (y en parte, para el de la novela histórica)" (Bajtin, 1985: 210). Para él:

[...] el último tipo de la novela de desarrollo [...es] el tipo realista. Los momentos de este desarrollo histórico del hombre están presentes casi en todas las grandes novelas del realismo, o sea, existen, por consiguiente, allí donde se introduce el concepto del tiempo histórico real (Bajtin, 1985: 215).

A partir de esta premisa, el teórico ruso advierte que el tipo más importante de novela de formación es aquél en el que se concibe el desarrollo humano: “[...] en una relación indisoluble con el devenir histórico. La transformación del hombre se realiza dentro del tiempo histórico real, con su carácter de necesidad, completo, con su futuro y también con su aspecto cronotópico" (Bajtin, 1985: 214).

Solo queda saltar, como novela de formación, procede con una estética realista al poner de relieve las lúcidas y valientes decisiones de los personajes según el devenir de su tiempo histórico en los años de la guerra y posguerra española y en el contexto histórico argentino a partir de la Conquista del Desierto; su desarrollo avanza paso a paso en la interrelación entre las acciones de los personajes y los hechos de la realidad externa. Los cronotopos de esta novela son la Europa de la segunda Guerra Mundial, la España de la Guerra Civil y el régimen franquista que le siguió y, a finales del siglo veinte y comienzos del veintiuno, el 
municipio de Fisterra en Galicia. En la Argentina, la acción se desarrolla, desde 1920, cuando llega al país el tío materno de las protagonistas, hasta la época actual, pasando por los gobiernos de Juan Domingo Perón junto a Eva Duarte en las décadas de 1940 y 1950, su breve presidencia en 1973 y la de su viuda, Isabel Martínez, que le sucedió hasta que fue derrocada por el golpe militar de 1976. Entre las llamadas "desapariciones" de opositores causadas por la represión militar de los años setenta, es relevante para la trama de la novela la ausencia/presencia fantasmal de Manuel, el primogénito de una de las protagonistas. Los espacios donde acontecen los hechos históricos en relación con el desarrollo de los personajes son Galicia, y en ella la localidad de Fisterra; Buenos Aires, capital de la Argentina, receptora de grandes oleadas de inmigrantes provenientes de Galicia y de todo el mundo; la ciudad de Chivilcoy en la provincia de Buenos Aires, y en el sur de la Argentina, la Patagonia, bordeada de pueblos y ciudades fronterizas que los indígenas saquearon durante años y luego buscaron como refugio cuando fueron dispersados y marginados por la arrolladora Conquista del Desierto.

\section{El motivo central de la guerra y sus secuelas}

La guerra, y los males que acarrea, es el motivo central de Solo queda saltar. En la novela se alude a varias guerras ocurridas en los siglos diecinueve y veinte. Además del exilio, los personajes sufren ataques, persecuciones, la pérdida o separación de sus seres queridos, cambios de territorio y de cultura y la consiguiente incertidumbre acerca de su propia identidad. Los principales conflictos europeos del siglo veinte que afectan a los personajes son las dos Guerras Mundiales y la Guerra Civil Española. En la Argentina, los personajes registran las huellas dejadas por las huelgas y protestas anarco-sindicales y la consiguiente represión militar en la década de 1920 en la Patagonia, los enfrentamientos entre peronistas y anti-peronistas a partir de la década de 1940, el accionar de los insurgentes y su aniquilamiento por las Fuerzas Armadas en la década de 1970 y, previamente, en el siglo diecinueve, la ocupación militar de los territorios indígenas en la llamada Conquista del Desierto que afectó la vida de varios personajes relacionados con la etnia indígena o mestiza. El exilio hacia lo desconocido es muchas veces la única salida de la situación límite que impone la guerra y así lo afirma el título de la novela.

Una angustiada pregunta surge de la lectura de Solo queda saltar: ¿Por qué el horror y la violencia de la guerra? ¿Cuáles son las causas que llevan a semejante destrucción y retorno a la barbarie? Aún hoy sigue siendo en España un tema controvertido el origen de la Guerra Civil iniciada en 1936 por un variado complejo de razones que no cabe discutir aquí. Es pertinente, en cambio, destacar que las crueldades que se comenten en la guerra y el resentimiento por esos actos generan una intensa respuesta psíquica personal y colectiva cuya descripción ocupa gran parte de la historia narrada en esta novela. En la España de la década del 30, sin que casi nadie advirtiera plenamente las consecuencias que traería el clima bélico que se iba acrecentando con el enfrentamiento de ideas e intereses de los grupos conjurados para la toma o conservación del poder, la paz civilizada se vio alterada y tanto hombres como mujeres, tanto niños como ancianos, se vieron envueltos en una ola de odio, rencor y violencia incontenibles. El miedo, que controlado lleva al coraje o si anega el ánimo es cobardía, se convierte en ansiedad y en pánico ante la amenaza de bombas o de matanzas a mano armada. Los actos de abuso sexual que se cometen en ese ambiente de agitación excedida no se explican por la teoría freudiana de la libido sino por la agresividad exacerbada por el temor (Hall, 1919: 218). Las víctimas favoritas de esos ataques, que culminan muchas veces en el femicidio, son las mujeres desamparadas en el desorden social de la guerra. Ellas, al igual que los niños y los ancianos, sufren la indefensión de la orfandad o del abandono pues los varones jóvenes de la familia están movilizados en la lucha, prisioneros del bando contrario o muertos.

El motivo de la guerra se tematiza, en primer lugar, en la historia central de dos hermanas, una adolescente y una niña, y sus sufrimientos en medio de la Guerra Civil española, donde una de ellas, Celia, padece un intento de violación que le genera un sentimiento de terror y culpa reprimido en su inconsciente que la traumatiza por años. La historia de las jóvenes culmina en un exilio salvador en la Argentina, la superación del trauma y su maduración en una identidad adulta firmemente arraigada en la pertenencia a una frontera transatlántica que las enriquece con su diversidad de etnias y culturas tanto europeas como americanas.

Otros personajes que aparecen en la novela dan testimonio también de sus sufrimientos por causa de la guerra. Gustavo, el inmigrante judío-alemán que de niño es enviado fuera de su país por la amenaza del incipiente régimen nazi, nunca más vuelve a ver a su padre, que muere en un campo de concentración. El tío de las niñas, el gallego Juan Lago Liñeiro, emigra a la Argentina en busca de ascenso económico y social, y antes de establecer su hogar en Chivilcoy, trabaja en las extensas estancias dedicadas a la cría de ovejas en la 
Patagonia. Allí participa en la gran revuelta obrera de 1920, reprimida por el ejército que pasa por las armas a los rebeldes sin aceptar treguas ni rendiciones. Juan logra huir y se mezcla con un grupo de anarquistas radicales que no dudan ante el crimen contra civiles como parte de la guerra. Una noche, toman por asalto una estancia y tras comer y beber, molestan a la muchacha que les había servido y luego la persiguen y balean cuando huye y trata de refugiarse en la oscuridad. Juan sufrirá por siempre el remordimiento y la duda de no poder saber jamás si fue su tiro el que la alcanzó. El personaje de doña María, la machi o médica mapuche, se presenta como víctima del ataque de una partida de soldados del ejército del General Roca cuando era una niña de once años que, al escapar, queda separada para siempre de su madre y de su hermano menor. Ella vivirá en la zona de "La Tribu" que abarca las tierras comunales en La Tapera de Díaz. Estas tierras, en reconocimiento por haber asegurado el triunfo de la batalla de Pavón, que significó el fin de la Confederación Argentina y la consagración de la provincia de Buenos Aires como miembro dominante del país, le fueron otorgadas al gran cacique mapuche boroano Ignacio Coliqueo ${ }^{2}$ por el General Mitre en 1862 (Hux, 1980: 70 y De Jong, 2015: 97-98 y 100). Muchos descendientes de Coliqueo viven aún hoy en esas tierras y en la periferia urbana de la ciudad de "Los Toldos". La zona se conoce como "La Tribu", debido al carácter comunitario de los derechos de propiedad otorgados (Yuln, 2015: 321-327). Doña María es la madrina de Ignacia, hija de Isidra Cayuqueo, quien, para defenderse ella y su hija de la violencia y los deseos pedófílos de su marido, se refugia en la casa y almacén de ramos generales de Juan Lago Liñeiro en Chivilcoy. Varios otros personajes han vivido dentro de la zona de "La Tribu", como Sara, casada con el hermano de Carmen Brey y Eva Duarte, la futura esposa de Juan Perón, nacida en la pequeña ciudad de Los Toldos y presentada en la novela como un personaje singular desde su niñez (Lojo, 2018: 66 y 132).

\section{Memoria, olvido y literatura}

No siempre la supresión o, por el contrario, el rescate oficial de la memoria colectiva logra un completo olvido o recuerdo de lo ocurrido. Tras una guerra, el olvido de un pasado doloroso es impuesto por la facción triunfante que busca inclinar la historia a su favor atribuyendo a su oponente los padecimientos sufridos, mientras que la memoria, rescatada por ley, es por lo común manipulada por el poder político. No solo la censura, sino además la autocensura impiden recuperar la memoria histórica de manera verídica y completa. Los monumentos o producciones artísticas que se han hecho para rememorar hechos históricos traen al presente versiones de la historia sujetas a una determinada percepción del significado de su expresión estética.

Según Maryse Bertrand de Muñoz, después de que se votó en España la ley de la "memoria histórica" del 31 de octubre de 2007, "las pasiones no se han apagado del todo y en algunos casos se han reavivado". En consecuencia, "La presencia de la 'memoria histórica' en la literatura supone un esfuerzo marcado para recordar y recuperar el pasado particularmente por los que han sido 'invisibilizados' durante el franquismo, o sea, los partidarios de la república" (Bertrand, 2011: 207). En la abundante literatura que ha surgido en España a propósito de la Guerra Civil, Bertrand detecta, que:

Durante las dos primeras décadas posteriores a la guerra, los novelistas situaban la trama de sus obras sobre todo 'durante' la guerra misma [... A] partir de los años setenta y mayormente desde la transición y el final del siglo XX, la tendencia más acentuada ha sido el partir del momento de la escritura para volver atrás, en una gran analepsis, a los años del conflicto o a los años inmediatamente posteriores, para encontrar la raíz y explicación del malestar psicológico actual de los personajes. (208)

\footnotetext{
${ }^{2}$ Los acontecimientos que rodean la vida de Ignacio Coliqueo (1796-1871), gran jefe mapuche boroano de Huincul, cerca de Temuco al sur de Chile: su traslado a la Argentina en la década de 1820, su asentamiento en Salinas Grandes en el suroeste de la actual provincia de Buenos Aires, su refugio, en 1834, en las tolderías del ranquel Yanquetruz en Leubucó, en el norte de la actual provincia de La Pampa, escapando afortunadamente de la Masacre de los boroanos en Masallé --perpetrada por el poderoso cacique mapuche Calfucurá por su política de alianzas y traiciones con las otras comunidades indígenas y con el gobierno de Buenos Aires-- forman parte del cronotopo de Finisterre, novela de María Rosa Lojo con personajes europeos que pasan años como cautivos en el campamento del Coronel Baigorria en la laguna de Trenel, cerca de Leubucó, dominio de los ranqueles. Allí, conoció Coliqueo a Manuel Baigorria, el desertor unitario perseguido por Rosas, que se convertiría en su yerno. Por las guerras entre Buenos Aires y la Confederación y de éstas con los indios, Coliqueo debió trasladarse más tarde a El Cuero, al sur de Córdoba (que Lucio V. Mansilla, el autor de Una excursión a los indios ranqueles, revisita paródicamente en otra novela de María Rosa Lojo, La pasión de los nómades) y luego, al entrar en trato con Mitre, peregrina con toda su tribu a las cercanías de Mar Chiquita, en la zona noroeste de Buenos Aires y finalmente a La Tapera de Díaz, donde se radica definitivamente, lugar donde transcurren algunos pasajes de Solo queda saltar. (Hux, 1980: passim).
} 
En Solo queda saltar, desde el punto de vista de la memoria individual, el recuerdo reprimido o silenciado de las experiencias dolorosas de Celia y de Ignacia a causa de la guerra o sus secuelas solo puede recuperarse por la vivencia de una experiencia similar que destraba la memoria, o por el "decir todo" a un interlocutor atento. Este silenciamiento de los hechos ocurridos y su recuperación tras una apertura a la liberación de la memoria prohibida puede considerarse como una metonimia de la represión o deformación oficial de los sufrimientos padecidos por todo un pueblo por la guerra, recuerdos que, por otra parte, son ocultados también por las víctimas, entre otras causas, por temor a las sanciones impuestas por quien tenga el poder.

\section{Cuaderno de Celia 1948: el reconocimiento narrativo de su identidad}

La primera parte de la novela es la transcripción del diario de Celia, la hermana mayor. Siguiendo las recomendaciones, ya citadas en el epígrafe, que le enviara secretamente su padre, prisionero por ser maestro de ideas republicanas, ella escribe en un cuaderno todo lo que le sucede. Las cartas mínimas del padre preso llevan su voz con el imperativo de escribir que permanece profundamente inscripto en la voluntad de la niña y la convierten en escritora y profesora de Lengua y Literatura (Lojo, 2018: 122).

La conmoción y el trauma causados por la experiencia de la guerra en la Galicia campesina y el exilio como peripecia mayor son aspectos importantes en el "Cuaderno de Celia 1948". Pasados unos años del fin de la Guerra Civil, al quedar huérfanas y solas tras la muerte de sus parientes, Celia, que ya es una adolescente, e Isolina, niña todavía, sin tener ya ni siquiera la frágil protección brindada por su madre y abuela, deciden embarcarse rumbo a la Argentina adonde había emigrado el hermano de su madre. Saben que el destierro es la única respuesta y que deben huir, que solo queda saltar con coraje al abismo que se abre hacia un lugar desconocido: "En el borde del mundo, en el borde de la vida, solo queda saltar. Esas alas que llevamos en secreto, cuerpo adentro, se abren únicamente cuando nos atrevemos a caer" (Lojo, 2018: 25). Al llegar a la casa de su tío Juan, Celia reconoce en él los ojos de su madre, recuerda la imagen juvenil de él en las fotos atesoradas por la abuela y llora de alivio en los brazos de su protector ya envejecido, porque "la fuga ha terminado" para ellas y para él también, tras su éxodo, ahora afincado y seguro en su nueva tierra y reunido con las descendientes de su familia gallega (Lojo, 2018: 14).

Las primeras líneas de Solo queda saltar colocan al lector en un tiempo y en un lugar que no corresponden al presente de la protagonista. Solo las itálicas dan una pauta de que ese episodio puede ocurrir en la memoria y no en la realidad. Y así es; más aún, sucede en un sueño de la autora del cuaderno que comenzamos a leer y que el título de la primera parte ubica en 1948, nueve años después del fin de la Guerra Civil española, cuando ya la narradora se ha exiliado y vive en Argentina. El sueño es simplemente el recuerdo borrado de un acontecimiento que ha ocurrido en el pasado, en la posguerra bajo el gobierno de Franco, cuando ya el padre de las jóvenes ha muerto en la cárcel y ellas viven solas en la casa campesina con su madre y su abuela.

El comienzo de la novela deja oír la voz interior de una jovencita que en una noche cerrada huye, subiendo por una áspera ladera, de los hombres que la persiguen para atacarla sexualmente. María Rosa Lojo, con sagacidad y empatía, nos transmite en la primera escena la percepción del mundo desde la sensibilidad de una niña en su primera adolescencia. Inerme como las demás mujeres en medio del espanto de una guerra que puede matarla igual que a los combatientes, toma conciencia de la vulnerabilidad de su cuerpo y es invadida por el miedo y por el ímpetu apremiante de salvar el sentido de su vida. Su cuerpo está en riesgo y su propio yo en peligro de disolución. Logra deshacerse de las garras y del peso aplastante del agresor y sube una cuesta llena de espinas. La agresión exterior estalla en una metáfora metonímica que ilumina el dolor de su inocencia amenazada: "en la mitad del pecho se me clava otro arbusto de cristales rotos" (Lojo, 2018: 9). Todo culmina en un terror seco y en el sentimiento de culpa de no haber podido ayudar a su prima Eulalia, que no pudo escapar de los hombres cazadores. El trauma causado por el ataque y la culpa por haberse salvado ella sola la llevarán a bloquear el recuerdo de lo sucedido que, por mucho tiempo, la perseguirá como un fantasma inconsciente en pesadillas reiteradas y angustiantes. La huella psíquica inconsciente dejada por el trauma del intento de violación aflora en sus sueños durante años. La adolescente sufre la opresión de esas pesadillas como un terrible sin sentido porque no recuerda el hecho real que las suscitó.

El rescate o anamnesis del evento pasado, que afectó tan profundamente a Celia y quedó constreñido a su representación en sueños angustiosos, se produce por otro evento que deja una impronta similar en su psiquis: el acercamiento de un hombre a su cuerpo. La asociación entre ambas emociones produce la rememoración y la reflexión sobre la verdad de los acontecimientos pasados. Celia cuenta que, por fin, durante una fiesta de la colectividad española en Chivilcoy, que recrea el espíritu de las romerías 
peninsulares, como la que precedió al suceso que la perturbó tan profundamente, la semejanza de la situación y el hecho de que su compañero la sacara a bailar, desató una crisis que significó el fin de la represión del recuerdo vedado. Tuvo una anamnesis del sentimiento de terror experimentado en el pasado con tal intensidad y realismo que huyó despavorida como en la ocasión real de peligro del que pudo escapar. Pasó dos días en un sopor semi-inconsciente y al despertar supo que la pesadilla que la atormentaba no era un sueño sino un recuerdo, "[u]na memoria que se pudrió y fermentó, sin ser reconocida. Una llaga con pus que fue creciendo en lo profundo muy por debajo de la piel hasta explotar" (Lojo, 2018: 88).

Al tomar conciencia de lo sucedido, logra por fin ponerlo en palabras, que le salen como una confesión, sintiéndose "como si fuera una criminal," la inunda la culpa y se ahoga en lágrimas de auto reproche que expresa gritando: "Yo me escapé. [...] ¡Pero dejé a Eulalia! La dejé. Me salvé sola" (Lojo, 2018: 88). El consuelo de los parientes que, a pesar de estar alejados en la Argentina, sabían todo lo ocurrido a Celia y a Eulalia, alivian a la joven del peso de su culpa. Su tío le asegura que ella no fue la causa de lo ocurrido ni pudo hacer otra cosa sino huir y salvarse, por lo menos ella.

El cuaderno de Celia plantea el tema de la memoria, el olvido y el reconocimiento del pasado vivido y de sí misma en su identidad como persona. Celia da testimonio de un presente gratificante que alterna en su diario con la narración de reiteradas pesadillas misteriosas, expresión del terror y la culpa causados por los eventos traumáticos pasados, más los sufrimientos de la experiencia de la guerra y del exilio cuando era apenas una adolescente. El "poder contar y poder contarse", según Ricoeur, se asocia con "la problemática de la identidad personal vinculada al acto de narrar $[, \ldots]$. En la forma reflexiva del 'contarse', la identidad personal se proyecta como identidad narrativa" (Ricoeur, 2006: 132). Celia logra recordar y a partir de ello construye y afirma su identidad y se promete un futuro mejor:

Por primera vez en tanto tiempo tengo piedad de mí. Y también de ellas: mi madre, mi abuela. Muertas de miedo, ocultándose y ocultándome. Clavando puertas y ventanas sobre la vergüenza de Eulalia, sobre mi propio terror. Protegiéndome de un futuro que para nosotras siempre iba a empeorar.

Ese futuro dejó de existir y tengo otro. Me haré otro. Si por el camino de las noches aparecen fantasmas, no serán esos. Volveré a la Casa das Ánimas, pero sabré quién soy. Ya no viviré huyendo. Me perdonaré. Estaré de pie frente a la que quiero ser. (Lojo, 2018: 89)

Entre los primeros episodios narrados por Celia en su Cuaderno, figura la entrada de Isolina a la escuela primaria argentina. Celia la presenta como una niña sin temor a ser diferente y que no acepta ser discriminada por ello:

Ni una hebra del pelo cobrizo y crespo se le escapaba de las trenzas bien apretadas. Sin embargo, no dejé de oír risas y murmullos a nuestro paso. "Zanahoria", "Mas bien remolacha" [...] Mi hermana es dura. Más de lo que parece. Más que yo. Siguió adelante sin desviar un segundo la mirada hasta el patio central donde la solté para que se sumara a las filas (Lojo, 2018: 52).

La ve también comprometida con las personas que la rodean, con las que crea todo tipo de lazos. Entre esos compromisos de Isolina, adquiere prominencia su amistad entrañable con la indígena Ignacia, de su misma edad, que había llegado con Isidra Cayuqueo, su madre, a la casa del tío Juan, huyendo de la persecución carnal de su padrastro. Ignacia se convierte de por vida en la compañera de estudios y colega profesional de Isolina. También destaca Celia la solidaridad que despiertan las niñas en Miguel Inchauspe, hijo de vascos, que protege a Isolina e Ignacia de las burlas de los otros escolares por el contraste étnico entre las dos amiguitas. Miguel será, en el futuro, el esposo de Isolina.

Al final de la primera parte, los dos últimos capítulos del diario de Celia constituyen una bisagra entre los relatos de ambas protagonistas, pues en ellos Celia narra la aventura de Isolina que, simplemente por lealtad a Ignacia, decide acompañarla y ayudarla a fugarse de la casa del tío Juan sin dar aviso a nadie, por motivos que la joven indígena no explica pero plantea como apremiantes, para salvarse ella y toda la familia de un terrible peligro inminente (Lojo, 2018: 90-91). La desaparición de las niñas sin dar una explicación de las razones ni del destino de su viaje pone en acción a toda la familia. Al trazar una estrategia para salir en busca de las fugitivas, la información recolectada por Celia nos pone en contacto con la vida en el interior de la provincia de Buenos Aires y específicamente en la zona de "La Tribu" donde antes vivía Ignacia. En la búsqueda, toman parte Celia, el tío Juan, Carmen Brey y Gustavo, su joven sobrino venido de Alemania y estudiante de medicina. Carmen es la única que conoce la región de "La Tribu" pues su hermano, Francisco Brey, que se une al grupo en la ciudad de Junín, había vivido en ese lugar, donde conoció a su esposa Sara, descendiente del jefe Coliqueo (Lojo, 2018: 94). La expedición de rescate creará la oportunidad para que Celia y Gustavo conversen y conozcan los detalles y semejanzas de sus vidas (Lojo, 2018: 92-93). Al final 
del rescate, la machi toma la mano de Gustavo para curar la herida espiritual que le dejó la guerra europea simbolizada en una cicatriz, habla de sus propias heridas al huir de los soldados del Gral. Roca y deja que Celia una su mano a las de ellos en un gesto que es metáfora de olvido y reconciliación con el pasado: "las tres palmas enlazadas acarician las sombras de los que dejaron atrás." (Lojo, 2018: 100).

Conviene insertar aquí lo narrado en las hojas sueltas que Isolina encontró junto al Cuaderno de Celia. En ellas, Celia narra los últimos episodios de su vida junto a Gustavo. El futuro de tranquilidad que parecía prometerse a Celia y Gustavo en su matrimonio se frustra por las secuelas de otra guerra, esta vez en Argentina. Quedan atrapados no ya por la represión de un mal recuerdo sino por el exterminio militar del accionar revolucionario argentino en los años setenta: su hijo mayor, Manuel, ha sido víctima de una "desaparición forzada", tecnicismo que significa la privación de la libertad por parte de fuerzas militares o agentes de un Estado autoritario, que no reconoce el hecho ni informa si la persona está detenida, torturada o muerta, en cuyo caso no dejan constancia del lugar donde fue arrojado su cadáver. Celia siente que ya no hay futuro, que su camino ha quedado interrumpido:

Solo hay un agujero negro. La ausencia de mi hijo, ni muerto ni vivo, un fantasma en el cielo y en la tierra, sin entidad. Desaparecido.

Desaparecido. Sin entidad. Sin nombre, sin justicia, sin derechos. Girando en la nada.

Ni vivo ni muerto.

Desaparecido. (Lojo, 2018: 140)

Celia percibe que su propia identidad está bajo amenaza: "[T]emo perder conciencia de quién era y de quién soy" (Lojo, 2018: 142). Ella y Gustavo han tenido otros dos hijos y trabajan intensamente enseñando a alumnos y curando enfermos, pero viven como autómatas bajo el régimen militar. Celia ya no tiene tiempo ni ánimo de escribir y piensa con alivio que es mejor que el tío Juan y las personas que la cuidaron en su niñez y juventud, los cariñosos y serviciales Trinidad y Braulio, no estén ya en este mundo para que no sufran las penas de ese presente. Después de ataques, clausuras y censura de libros, el Instituto de Cultura de Carmen Brey y de su esposo Ulrich von Phorner es ya "casi solo un Instituto de Idiomas, menos peligrosos que la Filosofía, la Sociología, la Literatura y la Historia" (Lojo, 2018: 142). Carmen y Ulrich se han ido haciendo viejos y sus hijos, junto con Celia y Gustavo, se encargan de manejar casi todo. Dando a entender el deterioro del sentido de identidad personal de Celia por la desaparición de su hijo, la novela la muestra sorprendida un día por el descubrimiento de que ya no están Carmen y Ulrich en sus habituales salones del piso alto. Encuentra en cambio el afecto de su esposo Gustavo que la recibe con los brazos abiertos, están solos y se dejan llevar por la música de Mozart: "Volamos juntos, en círculos crecientes, hacia la torre más antigua, guiados por la voz de la Reina de la Noche. Suelto las amarras, las notas del cuaderno, el cayado del peregrino. Ya no sabemos si somos el halcón o la tormenta, o un inmenso canto" (Lojo, 2018: 143). Es un simbólico final del camino de Celia, que había usado su narrativa como "un cayado de peregrino", el cual ya no precisa más, porque ha llegado al final de su camino (Lojo, 2018: 140).

\section{Cuaderno de Isolina 2018: su identidad interactiva, transcultural y abierta al futuro}

Isolina narra, desde la perspectiva de su vejez, las memorias de sus propias acciones y su espontánea interacción con las personas que la han rodeado desde que llegó a la Argentina a los diez años, hasta la avanzada edad en que comienza a escribir su cuaderno. Lo inicia en Fisterra, su tierra natal, que visita en compañía de Ignacia y donde se aloja en su antigua casa convertida en posada para turistas. Lleva la misión, entre otras, de enterrar, a pedido de Celia, el diario de ésta debajo del mágico crucero del jardín, en el camino hacia la familiar Casa das Ánimas, por cuya venta tanto había llorado la hermana mayor.

Isolina establece en sus anotaciones los lazos que han ido definiendo su personalidad y su posición en la sociedad, desde que era una niña inmigrante recién llegada, ignorante de la nueva cultura, pero confiada en sí misma y resuelta en sus decisiones. Relata así la firmeza con que vence los obstáculos temerosos que el tío Juan opone a sus planes de estudiar veterinaria en otra ciudad. Recibe para ello la ayuda de Celia, que argumenta que nada malo podría pasarle a quien había cruzado el mar y había sobrevivido a la guerra y a los peligros de su escapada con Ignacia. Logra así ir a estudiar a la Facultad de Agronomía y Veterinaria de La Plata junto con Ignacia y las dos se gradúan en tiempo, sin mayores dificultades.

El compromiso de Isolina con los demás se hace patente cuando recuerda los detalles, guardados minuciosamente en su memoria, de su fuga con Ignacia, de vuelta de ésta al lugar donde vivía antes con su madre, en busca de la protección de la gente de "La Tribu" que la conocía y podía protegerla del peligro que 
la amenazaba (Lojo, 2018: 107-111). La causa de la huida, confiesa después Ignacia, es la renovación de los asedios del marido de la madre de Ignacia, que había llegado hasta Chivilcoy persiguiendo a la jovencita. La figura patriarcal autoritaria e incestuosa encarna aquí una visión binaria de la familia y de la sociedad que llega a desatar, en distintos planos, atropellos a la dignidad personal de la mujer, enfrentamientos violentos de todo tipo, choques sectarios y por último la guerra.

Las fugitivas se alojan en casa de Doña María, la médica indígena madrina de Ignacia, pero recién después de la llegada de Celia y Gustavo a su rescate, se atreve Ignacia a hablar de la situación que la avergüenza. La machi la alienta a que se exprese sin miedo para poder curar su psiquis: "El habla tiene que salirle del cuerpo. [...] Que ella diga, porque la palabra hace más fuertes a las personas. Y las cura. Hay que sacarla de adentro para limpiar el alma, como se limpian las heridas" (Lojo, 2018: 114).

La escena de la recuperación de Ignacia, al igual que la de Celia, devela un tema esencial en la obra de Lojo: la importancia de la palabra que transforma lo interpsíquico en intrapsíquico porque el diálogo ayuda a tomar conciencia y forjar la identidad (Vygotsky, 1993: T II). Los grandes representantes de la psicología evolutiva como el suizo Jean Piaget y el ruso Lev Vygotsky han reconocido la importancia del lenguaje como estímulo fundamental del despertar y el crecimiento de la inteligencia y la conciencia humanas desde la niñez. Vygotsky, iniciador de la investigación psicolingüística, señala el papel primordial del lenguaje en el proceso de maduración individual y dice: "Las palabras tienen un papel destacado tanto en el desarrollo del pensamiento como en el desarrollo histórico de la conciencia en su totalidad. Una palabra es un microcosmos de conciencia humana" (Vygotsky, 1964: 164-165).

El hecho de contar lo acontecido es una de las premisas de la terapia en el psicoanálisis de S. Freud y J. J. Lacan, en la logoterapia de Víctor Frankl y en el análisis existencial de Alfried Längle. Los psicoterapeutas han acentuado el valor curativo de poner en palabras las aflicciones pasadas que la consciencia niega. Al respecto, Paul Ricoeur observa:

Es cierto que, en el marco preciso de la cura terapéutica, el deber de memoria se formula como una tarea: señala la voluntad del paciente de contribuir en lo sucesivo a la empresa conjunta del análisis [...] Esa voluntad llega a adoptar, incluso, la forma del imperativo: el de que las representaciones del inconsciente se manifiesten, y así, en cuanto es posible, "decir todo" (Ricoeur, 2004: 118).

Cuando el feliz grupo de Ignacia, Isolina, Celia y Gustavo sale de la casa de Doña María y se encamina al punto de encuentro con el resto de la familia, Goyo, el padrastro de Ignacia, aparece repentinamente en el camino y les dispara a mansalva. Gustavo es herido en un brazo, pero así y todo cubre a las mujeres con su cuerpo y las arrastra a la protección de los pastos altos fuera de la senda.

En este punto de su relato, Isolina toma conciencia como narradora de la trama que enlaza los acontecimientos como "las fichas de un juego que se había iniciado sin nosotras, años atrás, dibujando un mapa que iba a durar por mucho tiempo, con la intervención de nuevos actores", y agrega: "Todo fue como un sueño de terror, donde se encadenaron sucesos imprevisibles" (Lojo, 2018: 117). La visión que en ese momento de gran tensión tiene Isolina de la realidad como un juego ficcional que la envuelve a ella y a sus compañeros de aventura revela una toma de conciencia metaficcional que incorpora el hacer mismo del escritor a su narrativa. La hispanista canadiense Maryse Bertrand de Muñoz, experta en la literatura española de la Guerra Civil, considera que "La estrategia narrativa más notoria en la primera década del siglo XXI en las obras narrativas de la cruenta guerra viene a ser la metaficción, o sea, la autoconciencia de la fícción y el juego entre la realidad y la ficción" (Bertrand, 2011: 214). Luego, citando a Geneviève Champeau, profesora e investigadora especializada en literatura peninsular del siglo XX en la Université Michel de Montaigne, Bordeaux III, Bertrand de Muñoz afirma a continuación que:

Los relatos en los cuales se utiliza la reflexividad, dice [Champeau], "miran hacia su "ser" y sobre su "hacer", llevando la atención del lector del universo diegético hacia "la nature et les principes du fonctionnement de l'objet littéraire et de la communication qu'il instaure' (65) (Bertrand, 2011: 214).

El uso de la metaficción en Solo queda saltar, como en la novela de la Guerra Civil española en el siglo XXI, revela una captación de la realidad como un juego ficticio, inverosímil o increíble y, al mismo tiempo, una mayor conciencia acerca de los instrumentos y posibilidades del oficio literario que permite ir más allá del pacto mimético del realismo.

El nuevo actor que entrará en el juego narrativo de Isolina es un hombre joven que intercepta a Goyo cuando empieza a disparar, lo desarma y lucha con él a cuchillo hasta que ambos caen heridos. Gustavo se acerca para auxiliarlos y constata que Goyo está muerto y que una cuchillada ha afectado el pulmón del desconocido que necesita atención urgente. Isolina se constituye en el agente catalizador que modifica 
rápidamente una situación: sale corriendo por la carretera sin esperar la aprobación de nadie y alcanza a los que venían en camioneta, Juan, Carmen y Francisco Brey. La decidida acción de Isolina salva la vida del desconocido que se recupera en el hospital. En su sala de enfermo, Isolina y Celia observan el llanto del tío Juan junto al lecho del desconocido. Celia lo reconoce como Ramón Olvera, el hombre de una foto que un día le había entregado Carmen Brey para que Juan conociera el aspecto del hombre que trabajaba con Francisco Brey en Junín. Pero su verdadero nombre es Enrique Lago y es el hijo que había abandonado a Juan, su padre, mucho tiempo atrás, cuando murió su madre y quiso su independencia. La anagnórisis marca el retorno de Enrique al hogar como un héroe tras liberar a Ignacia y sus acompañantes de un alevoso ataque. Se reconcilia con su padre y vuelve a ser parte del negocio, sin resentimientos: logran escuchar y ser escuchados con respeto mutuo.

En el cuaderno de Isolina las acciones de cada personaje se suceden sin tregua: Celia aprueba los exámenes de equivalencias para terminar su secundario en Argentina, entra a estudiar en el Profesorado de Lengua y Literatura y, al mismo tiempo, consolida su relación amorosa con Gustavo.

También da cuenta Isolina de la agitación política del momento: el auge del peronismo despierta fanatismos partidarios y el rechazo de los moderados que ya han experimentado la desintegración social de las guerras. Tanto el "Almacén de Ramos Generales Juan Lago e Hijo" como el "Instituto de Cultura" de Carmen y Ulrich se niegan a exhibir carteles con las fotos del entonces Presidente Juan Perón y su esposa Eva Duarte. Sin embargo, Enrique incita a su padre a aceptar los carteles y a colgarlos discretamente para evitar multas y represalias contra el negocio. Los Phorner no lo aceptan y sufren las consecuencias: las ventanas de su Instituto son apedreadas y uno de sus estudiantes es herido por los vidrios. Carmen viaja a la Capital y, en recuerdo de la amistad que había trabado con la pequeña Eva Duarte, que la ayudó a buscar a su hermano que vivía en Los Toldos, la esposa del Presidente suspende las agresiones (Lojo, 2018: 132). Con realismo y decepción, Isolina comenta en su relato "la violenta intolerancia de los argentinos entre sí" que resulta en incendios, bombardeos y finalmente en 1955 el golpe de Estado contra Perón y el secuestro del cuerpo embalsamado de Eva. El levantamiento de grupos insurgentes en las décadas siguientes genera otro golpe de Estado y una represión a muerte, "[h] asta que los muertos se convirtieron en fantasmas insepultos" (Lojo, 2018: 133).

El cuaderno de Isolina da una visión muy crítica de la guerra, que interrumpe la comunión ética entre las personas y la reemplaza con la falsa unidad del fanatismo. Conforme a ello, resalta sobre todo los lazos que unen a las personas. Narra la relación de pareja del tío Juan y Angelita, su ex empleada, y la difícil aceptación de esta relación por parte de Enrique, que finalmente reconoce el respeto de Angelita por el recuerdo de su madre, a la que no pretende reemplazar. Completa los detalles de la escapada de Isolina e Ignacia con la acción oportuna y valiente de Gustavo, que lo acercará amorosamente a Celia y a través de la alegría de Angelita da a conocer el matrimonio de Gustavo y Celia y el nacimiento de su primer hijo, Manuel. Pero la guerra sigue siendo una presencia dominante en la novela. Más adelante, estando en Fisterra, a propósito del eterno emigrar y retornar de los gallegos a su patria, comentará Isolina: "Ojalá hubiera podido venirse aquí, a tiempo para salvarse, mi sobrino Manuel" (Lojo, 2018: 129). Narra también, aunque brevemente, su matrimonio con Miguel Inchauspe, que en su infancia la defendía de las burlas discriminatorias de sus compañeros de escuela, sus momentos de diversión con sus hijos y nietos, la cardiopatía de su marido por la que viaja a Fisterra sin él, acompañada solamente por Ignacia, la relación de pareja de ésta con Hannah, una veterinaria e investigadora inglesa. En los últimos capítulos las dos viejas amigas prevén un futuro tranquilo, cada una con sus seres queridos en Argentina y en Inglaterra y sin otras sorpresas que el humano límite del tiempo vital.

La capacidad de comunicarse le interesa especialmente a Isolina que destaca el salto tecnológico que en ese sentido se produjo a fines del siglo veinte con la internet y su acceso desde el increíble celular, "un aparato mínimo y manuable que funciona como teléfono, pero que también puede ser [...]" y detalla casi una veintena de aparatos que a mediados del siglo veinte eran todavía una novedad fascinante y que ahora han sido reemplazados por el celular (Lojo, 2018: 138-9). Hay un deseo de comunión e inclusión de lo diverso en la narrativa de Isolina y al mismo tiempo una visión contrastiva y con un giro de humor de las paradojas del mundo moderno. El terror de la humanidad ante una posible guerra atómica, contrasta en los mismos años con las exploraciones espaciales de los astronautas norteamericanos y rusos; los asesinatos de Kennedy y Martin Luther King y la guerra de Vietnam ocurren "mientras John Lennon cantaba Give Peace a chance y los hippies exhortaban a hacer el amor y no la guerra" (Lojo, 2018: 139). Mientras la moda permitía a las chicas mostrar sus piernas y a los muchachos dejar crecer su cabellera, otros luchaban con o sin armas por la equidad social. "También a la Argentina de las dictaduras llegó ese sueño y muchos jóvenes murieron por él" (Lojo, 2028: 140). 
Isolina se ha sentido parte del entorno cultural argentino, pero mientras pasea como turista por su Fisterra nativa, su visión abierta a la diversidad del mundo en sus distintas características histórico-culturales, la lleva a concebir un nuevo tipo de identidad y de pertenencia transcultural. Al final de su cuaderno, esboza un proyecto literario en el que espera describir, no animales reales como los que ha analizado en sus estudios como veterinaria profesional, sino seres fantásticos como las Siniguales $^{3}$ que habían iluminado las quimeras de su infancia. La imagen de la Sinigual viajando en su dorna, réplica en miniatura de las naves vikingas, afirma la identidad de Isolina, que ha superado el temor e inseguridad del exilio y vive en una amplia frontera transatlántica en una forma de territorialización dinámica. Su sentido metaficcional de la trama narrativa, problemática como una adivinanza o acertijo, que ha ido creando en el relato de sus memorias, la lleva a desentrañar también el sentido de su vida:

Como un rompecabezas que se arma de golpe, cuando ya se han perdido las esperanzas de comprender, lo entiendo.

Yo soy el vaivén.

Cuando me voy, nada dejo, porque todo viaja conmigo.

Soy la casa sin anclas, soy mi propia barca que cruza los abismos llevando la memoria de todas las orillas (Lojo, 2018: 149).

No siempre el desastre de la guerra produce una represión inconsciente, como en el caso de Celia. La actitud de Isolina ante el dolor del desamparo, orfandad y exilio que le produjo la guerra no es la represión del recuerdo sino la opción por el olvido de lo inevitable que ya sucedió y la elección de un camino diferente hacia un futuro más promisorio. Entiende que las migraciones seguirán expulsando "a los perdedores de todas las guerras" (Lojo, 2018: 129), tanto a los españoles como a los indígenas americanos, y que "migramos para sobrevivir. Como las libélulas pantala o las mariposas monarca" (Lojo, 2018: 149). Su elección arranca de una intención de olvidar y perdonar. Por eso, cuando joven, al escoger un campo de estudio y de trabajo, ya había mostrado su preferencia por los seres no humanos, cuya eventual crueldad no se equipara a la desatada en las guerras entre hombres:

A mí dame a leer el libro de las criaturas. Las que se mueven en el cielo y en la tierra. Las que matamos para comer y las que dejamos vivir. Las que mugen, las que balan las que graznan. Las que forman bandadas en los cielos de la primavera. Esas son mis letras. Ellas hablan a su manera, quizás mejor que nosotros (Lojo, 2018: 103).

Al final de su vida, cuando resuelve comenzar a escribir sus recuerdos, los vuelca al exterior, a los acontecimientos, a la realidad de los hechos pasados más que a la subjetividad de los actores. Cumple así con una de las premisas de veracidad de la memoria histórica: no dejarla librada a la imaginación porque como dice Ricoeur: "debe procederse, lo más que sea posible, a la separación de la imaginación y la memoria" que se diferencian por sus objetivos y sus intencionalidades: "uno, el de la imaginación, dirigida hacia lo fantástico, la ficción, lo irreal, lo posible, lo utópico; otro, el de la memoria, hacia la realidad anterior, ya que la anterioridad constituye la manera temporal por excelencia de la "cosa recordada"" (Ricoeur, 2012: 22).

Conforme a su actitud orientada hacia la esperanza y el futuro, Isolina tiende a lo imaginario con lo que se identifica. Cuando niña ya había hecho una elección similar: durante la celebración del Carnaval, mientras todos los demás dudaban si deberían disfrazarse de lo que son, gallegos, o si elegirían cubrirse o mostrar lo mejor de ellos, Isolina se había vestido de "Sinigual":

[...un] velo gris oscuro que se ajusta sobre la cara como una máscara de gasa [...] todo cuanto asoma fuera de las ropas, cubierto con vendas de similar material. [...R]esulta dudoso considerar como ropas el rompecabezas de retazos múltiples que llega desde su cuello hasta los pies, en fragmentos multicolores de raso, de satén, de algodón, de paño.

Bajo un bonete alargado, similar al de un hada o una bruja, salen varios inequívocos mechones cobrizos de pelo natural que solo pueden pertenecer a Isolina, mezclados con hebras de lana blanca.

[...]--¿Pues qué eres? [...]

--Soy una Senigual. $[\ldots]$

\footnotetext{
${ }^{3}$ Referencia a El libro de las Siniguales y el único Sinigual, microficciones que conjugan la escritura de María Rosa Lojo y las obras visuales de su hija Leonor Beuter, Buenos Aires: Mar Maior, 2016.
} 
$--¿$ Y qué hacen las Siniguales?

--Son.

--¿Qué son?

--Siniguales. No se parecen a nadie, sino a ellas mismas. [...] Son muy viajeras y muy pequeñas. Cabían en la palma de mi mano. Olían bien. A perfume de canela, a filloas recién hechas. Me calentaron la mano, que estaba helada. Me quitaron las penas. Pero se fueron, en una dorna que volaba. Y cruzaron el mar en dirección de América. No saben que estoy aquí. América es tan grande. Si me visto como ellas, a lo mejor se enteran y vienen a buscarme (Lojo, 2018: 51).

La Sinigual es un ser fantástico inexistente que le permite a Isolina adquirir una identidad única, inaccesible al odio de los estereotipos y etiquetas. Al terminar de escribir sus memorias, ya cerca del límite de su tiempo de vida, se aleja de la historia real y proyecta la creación de muchos seres de esa especie quimérica: las Siniguales:

Cerraré este cuaderno y abriré otro. No será un relato de viaje sino el "Libro de las Siniguales": los seres que intento conocer desde hace más de setenta años, cuando los encontré o me encontraron en Fisterra. Un libro que sería de ciencia como los de Hannah o Ignacia, si no tuviese que usar instrumentos ajenos a mi oficio: la adivinación y la poesía (Lojo, 2018: 150).

\section{Una reflexión final}

En el siglo XXI, han vuelto a aparecer en España obras en las cuales "todo" o casi todo el texto se desarrolla directamente durante los hechos bélicos y Bertrand considera que "la insistencia en la 'memoria histórica', en los sufrimientos de los derrotados, es uno de los temas de mayor relieve en el siglo XXI" (Bertrand, 2011: 209). Y agrega:

Unos cuantos autores utilizan la memoria como reivindicación del dolor pasado, vuelven al tiempo de "la voz dormida," como reza el título de la obra de la fallecida Dulce Chacón; ese tiempo de silencio nutre mayormente la inspiración de muchísimos novelistas que, como José María Merino, se han sentido "hijos de la guerra civil," en los cuales "persistía un sentimiento de desgarro, de provenir de una catástrofe, de habernos formado en un territorio arruinado y con muchos espacios de memoria borrada ("Noticias de Sabino" 5). (Bertrand, 2011: 209).

Solo queda saltar, a pesar de haber sido narrada desde un exilio en América, podría incorporarse a este grupo ya que la familia de las protagonistas y ellas mismas son víctimas de la guerra fratricida y la autora, María Rosa Lojo, se considera a sí misma una "exiliada hija", ya que nació en el exilio, de padres de opuesto color político que trasladaron a su país de acogida mucho del sufrimiento, recuerdos y olvidos de lo vivido en España.

Al mismo tiempo, la redención vital de los personajes femeninos indígenas traumatizados, Isidra e Ignacia, es una expurgación de la culpa colectiva de la sociedad latinoamericana por la violencia bélica y por la marginación de los aborígenes y especialmente de las mujeres. La amistad de las niñas Isolina e Ignacia, la española y la nativa, su educación y ejercicio profesional y su viaje juntas a España en su vejez culminan de este modo el ciclo personal de rescate de los traumas históricamente sufridos por la mujer, por el violento reduccionismo de sus posibilidades de desarrollo pleno en un medio social que la margina, ignora y vulnera.

Desde este punto de vista, esta novela, como tantas otras narraciones de María Rosa Lojo, puede ser incluida dentro de la literatura escrita en España y en Latinoamérica para denunciar la victimización de mujeres en el desorden de las guerras y los movimientos revolucionarios, para buscar el reconocimiento de la valiosa actividad femenina aun en las guerras y posguerras, para promover el derecho de la mujer, incluyendo a la indígena, a una educación de calidad, y para exaltar el coraje con que la mujer se anima a enfrentar las circunstancias y dificultades extremas y extenuantes a las que la someten su dependencia de un orden social masculino que la deja a la intemperie cuando se entablan luchas de poder que no la tienen en cuenta.

Solo queda saltar es una gran novela que, con maestría, condensa, en la intensidad de sus breves páginas, los desgarramientos vitales que producen la guerra, el abuso sexual, la pérdida de la familia, el desamparo de la orfandad y, por último, el coraje sin igual que impulsa a quienes solo encuentran en el exilio un posible escape de una situación histórica asfixiante. Como novela de formación, va siguiendo los pasos en el difícil desarrollo de dos muchachas españolas huérfanas y de una amiga indígena que, desde su desamparo se abren al mundo, recorriendo con esfuerzo y decisión un camino, al comienzo del cual encontraron agresiones 
sexuales y pérdida de seres queridos por revoluciones y guerras. Se trata de los relatos de dos narradoras femeninas en primera persona que van dando testimonio de un proceso de aprendizaje y maduración con el apoyo de los afectos familiares y de una red de auxiliares, vecinos y maestros. Se destacan en la novela estos mediadores y traductores transculturales indispensables para que los inmigrantes formen su identidad en el nuevo medio y se afinquen firmemente en el territorio inexplorado, sin romper con la magia, las leyendas y los mitos de su imaginario original que los nutre y encanta.

Las palabras de Carmen Brey, que encarna el papel de mentora de Celia y guía de su formación intelectual y espiritual, ofrecen recursos para enfrentar las dificultades de la vida con fortaleza y preservar la identidad, aun siendo peregrinos, ya que todos deberán dejar su hogar alguna vez y, finalmente, dar el salto mortal fuera del tiempo:

No hay quien no lleve dentro su Fisterra. Aunque no haya salido nunca de sus ciudad o de su aldea. Pobres o ricos, protegidos o a la intemperie, llega el momento en que se nos exige más de lo que creemos que podemos dar. En que chocamos contra lo desconocido y afrontamos el terror de no ser más. No ser ya quienes éramos y no poder ser otros. No encontrar las nuevas claves para seguir viviendo. Y es así a cualquier edad, desde el principio hasta el fin. También debemos aprender cómo envejecer y cómo morir (Lojo, 2018: 38).

\section{Referencias bibliográficas}

Bajtín, Mijaíl Mijáilovich (1985), "Hacia una metodología de las ciencias humanas", en Estética de la creación verbal. $2^{\mathrm{a}}$ edc. México: Siglo XXI, págs. 381-396.

(1985), "La novela de educación y su importancia en la historia del realismo", en Estética de la creación verbal. $2^{\mathrm{a}}$ edc. México: Siglo XXI, págs. 200-247.

Bertrand de Muñoz, Maryse (2011), "Las grandes tendencias de la novela de la guerra civil en el siglo XXI", Revista Canadiense de Estudios Hispánicos, vol. 36, nº. 1, La guerra civil española: un dolor que no se calla (Otoño 2011), págs. 207-225.

Champeau, Geneviève (2001), "L'autoreprésentation dans le récit de fiction", en Annie Bussière- Perrin (coord.). Le roman espagnol actuel. Pratique d'écriture. 1975-2000. Montpellier: Centre d'études et de recherches sociocritiques, 2001, págs. 65-98.

De Jong, Ingrid (2015), "El acceso a la tierra entre los indios amigos de la frontera bonaerense (1850-1880)", Revista de Ciencias Sociales, segunda época, año 7, $\mathrm{n}^{\circ}$. 27, Bernal, Editorial de la Universidad Nacional de Quilmes, otoño de 2015, págs. 87-117.

Hall, G. Stanley (1919), "Some Relations between the War and Psychology", The American Journal of Psychology, vol. 30, $\mathrm{n}^{\mathrm{o}} .2$ (Apr., 1919), págs. 211-223. Disponible en: https://www.jstor.org/stable/1414115

Hux, P. Meinrado (1980). Coliqueo, el indio amigo de Los Toldos. $3^{\mathrm{a}}$ edc. Buenos Aires: Eudeba.

Lojo, María Rosa (2018). Solo queda saltar. Buenos Aires: Santillana.

-----, -------- (2011). Bosque de ojos: Microficciones y otros textos breves. $1^{a}$ edc. Buenos Aires: Sudamericana.

(2006), "Mínima autobiografía de una "exiliada hija”, en Manuel Fuentes y Paco Tovar (eds.). L'exili literari republicà. Tarragona: URV, 2006, págs.87-97.

Morgenstern, Karl and Tobias Boes (2009), "On the Nature of the 'Bildungsroman"”, PMLA, vol. 124, n'. 2 (Mar., 2009), págs. 647-659 Disponible en: https://www.jstor.org/stable/25614309

Ricoeur, Paul (2004). La memoria, la historia, el olvido. México: Fondo de Cultura Económica.

--------, (2006). Caminos del reconocimiento: Tres estudios. México: Fondo de Cultura Económica.

Vygotsky, Lev S. (1995). Pensamiento y lenguaje. Barcelona: Paidós.

Yuln, Melina y Graciela Silvestri (2015), "Una forma territorial alternativa: la tribu de Coliqueo en la pampa bonaerense”, Antítesis, vol. 8, nº. 15, págs. 313-344, jan./jun., 2015. 